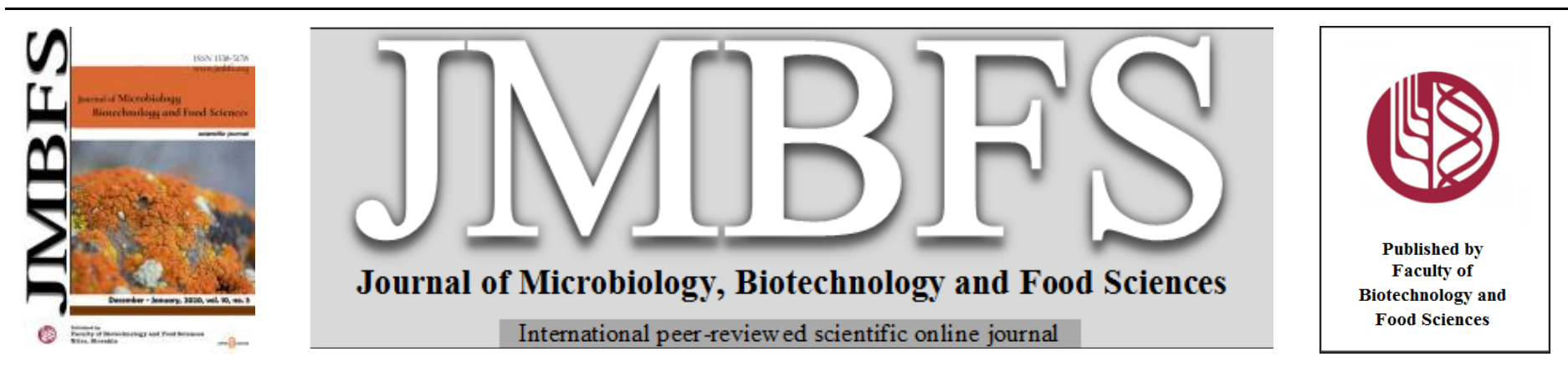

\title{
SURVIVAL ASSESSMENT OF PATHOGENIC BACTERIA WITH ANTIBIOTIC RESISTANCE TRAITS FROM FRESH SUMMER ROYAL GRAPE: IN VITRO MICROBIAL CHALLENGE TEST
}

\author{
Taslima Akter ${ }^{a}$, Asif Shahriar ${ }^{a}$, Tasmina Rahman ${ }^{b}$, Md. Rayhan Mahmud ${ }^{c}$, Mahenaj Alo ${ }^{a}$,Talha Bin Emran ${ }^{d^{*}}$
}

Address(es):

${ }^{a}$ Department of Microbiology, Stamford University Bangladesh, 51 Siddeswari Road, Dhaka-1217, Bangladesh

${ }^{\mathrm{b}}$ Faculty of Health and Medical Sciences, UWA Medical School, University of Western Australia,Perth WA 6009, Australia

${ }^{c}$ Department of Microbiology and Biotechnology, Biocenter 1 FI-00014, University of Helsinki, Finland

${ }^{\mathrm{d}}$ Department of Pharmacy, BGC Trust University Bangladesh, Chittagong-4381, Bangladesh

*Corresponding author: mailto:talhabmb@gmail.com or talhabmb@bgctub.ac.bd

doi: 10.15414/jmbfs.2020.10.3.344-349

ARTICLE INFO

Received 28. 12. 2019

Revised 1. 7. 2020

Accepted 3. 7. 2020

Published 1. 12. 2020

Regular article

open $O$ access

\begin{abstract}
Table grape act as a popular and mouthwatering fruit supplement over the world. Unhygienic handling of these fruits can possess a diverse threat to public health safety. Moreover, the fruit juice can serve as a nutrient for bacterial growth as well if kept in an unsanitary condition. For this purpose, five imported grape samples (Red Globe, Perlette, Calmeria, Princess and Summer Royal) were tested to assess the presence of pathogenic bacteria and drug-resistant pattern of the isolates. The total bacterial count (TBC) and total fungal count (TFC) showed the presence large amount of bacterial (ranged from $4.4 \times 10^{4}$ to $8.1 \times 10^{7}$ ) and fungal population on the grapes samples, especially on the skin part of the fruits. Several pathogenic isolates, Escherichia coli, Staphylococcus spp., and Pseudomonas spp. were isolated from tested grape samples. However, the presence of Salmonella spp., Shigella spp., Vibrio spp. and Klebsiella spp. were not found from any of the samples. The concerning part of the present study was drug-resistant bacterial strains isolated from supplied Fresh Summer Royal Grape. The most of the isolated bacterial spp. were resistant to all most all of the commonly used antibiotics such as ampicillin $(10 \mu \mathrm{g})$, trimethoprim/sulfamethoxazole $(25 \mu \mathrm{g})$, tetracycline $(30 \mu \mathrm{g})$, ceftriaxone $(30 \mu \mathrm{g})$, imipenem $(10 \mu \mathrm{g})$, chloramphenicol $(30 \mu \mathrm{g})$, azithromycin $(15 \mu \mathrm{g})$, novobiocin $(30 \mu \mathrm{g})$, vancomycin $(30 \mu \mathrm{g})$, penicillin $\mathrm{G}(10 \mu \mathrm{g})$, ciprofloxacin $(5$ $\mu \mathrm{g})$, neomycin $(30 \mu \mathrm{g})$, levofloxacin $(5 \mu \mathrm{g})$, kanamycin $(30 \mu \mathrm{g})$ and cefiximycin $(5 \mu \mathrm{g})$. No grape samples showed any kind of antimicrobial activity against both pathogenic and non-pathogenic bacteria. The survival pattern of inoculated bacterial samples in the grape sample showed a slight decrease in growth in the course of time.
\end{abstract}

Keywords: Summer Royal grape, Grape-borne bacteria, Pathogenic Microorganisms, Antibiotic susceptibility, Microbial challenge test

\section{INTRODUCTION}

Grape, Vitis vinifera, are the most common fruits all over the world since centuries ago. They are believed to be originated from Northwest Asia and have been cultivated in many regions of Central Asia, Australia, the United States of America and countries of Europe (Samad et al., 2012). Recently some tropical countries like Thailand and Malaysia have started to cultivate grape, while Bangladesh is now under trial to accomplish the success of grape cultivation. Grapes contain susceptible anti-oxidant that minimize multiple disease risks (Fatema et al., 2013). The fruits like grapes belong to the berry family; constitute a cluster or bunch of grapes. It has many nutritional, healthy and medicinal properties and broadly accepted as one of the most eatable foods to the trenchermen. Grape contains $82 \%$ water, $12-18 \%$ carbohydrates, $0.5-0.6 \%$ proteins and $0.3-0.4 \%$ fat. Therefore, it's a good source of potassium, vitamin A, vitamin $\mathrm{C}$, calcium and phosphorus. It contains the significant amount of all those elements; $0.1-0.2 \%$; $0.001-0.0015 \% ; 0.01-0.02 \% ; 0.01-0.02 \%$ and $0.08-0.01 \%$ respectively (Mukesh Y. et al., 2009). Nutrients like boron are also found in grapes (Demir \& Serindag et al., 2006), which are a possible element for bone health and bone marrow establishment (Mukesh Y. et al., 2009). One of the major nutritional value including 78 calories of energy, protein $(0.3 \mathrm{gm})$, carbohydrate $(19 \mathrm{gm}), 3 \%$ calories from fat $(0.23 \mathrm{~g}$ of fat), sodium $(0.18 \mathrm{mg})$, potassium $(155 \mathrm{mg})$, fibre $(0.4 \mathrm{gm})$, calcium $(20 \mathrm{ng})$, phosphorus $(30 \mathrm{ng})$ and vitamin $\mathrm{C}(1 \mathrm{gm})$ have been yielded from per halves of grape. Furthermore, phytochemicals like gallic acid, catechin, and epicatechin are originated from skin and seeds of grape and these phytochemicals have been reported as the raw substrates to produce antioxidative dietary supplements (Yilmaz \& Toledo $e$ al., 2004; Mukesh Y. et al., 2009). White grape pomace could yielded antioxidant thioconjugates (Selga et al., 2004, Mukesh Y. et al., 2009). Many researchers proved that Concord grape juice plenty amount of flavonoids, which has the significant antioxidant potency with a-tocopherol (vitamin
E) (O’Byrne et al., 2002, Mukesh Y. et al., 2009). Flavonoid effectively works as a strong antioxidant and have the ability to protect the host from oxidative stress. Also, free radical damages and onslaught of chronic diseases have been decreased by Concord grape juice. Surprisingly, dried grape seeds have flavanol content with high antioxidant activity; acquired after the colour extraction and alcohol distillation of wine production even after exposure to advanced temperatures (Gonzalez - Paramas \& Rivas - Gonzalo et al., 2004, Mukesh Y. et al., 2009). Although, grapes containing, all the isolating compounds are not medically significant, very few of them having biological or medicinal activities Anticarcinogenic, antioxidant, antidiabetics, anti-atherogenic, neuroprotective, anti-ageing, anti-obesity, immunomodulatory and anti-infection are the constituents of medicinal properties of grape (Mukesh Y. et al., 2009) (Figure 1). Particularly, more evident biological activities of resveratrol have been extracted from the skin and seeds of the grape.

Two individual grapes include Table grape and Wine grape, are consumed; Table grapes are eaten up fresh, utilized to prepare jam and used in recipes. Grape is considered as a pack of nutrients, such as sugars, mineral salts, enzymes, vitamins and phytochemicals which give the sensory properties of wine (Waterhouse et al., 2002 and Walzem et al., 2008). Grape products are rich in phenolic compounds which draw an attraction because of their beneficial health benefits (Fuleki \& Ricardo-da-Silva, 2003 and O'Byrne et al., 2002). Several antioxidants, namely flavonoids, epicatechin, anthocyanin, carotenoids are present in high amount in grape extract (Lopez-Velez et al., 2003; Park et al., 2003 and Viljanen et al., 2002). Multiple clinical examinations reported the benefit of consumption of fruit with high phenolic content, especially resveratrol, by decreasing the risk of developing cardiovascular disease (Garcia-Alonso et al., 2004 and Bertelli \& Das et al., 2009). Furthermore, grape seed extract has been premeditated to lower the risk of several cancer and Alzheimer's disease as well (Marambaud et al., 2005). 


\section{Anti-oxidant}

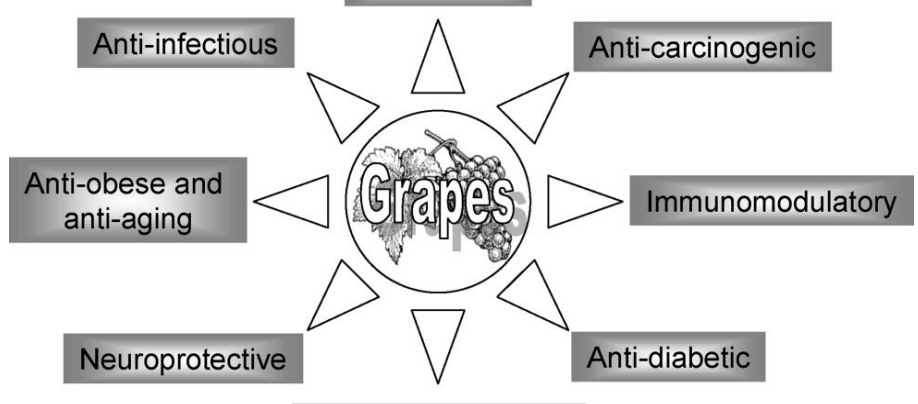

Anti-antiatherogenic

Figure 1 Medicinal properties and effective applications of grapes.

Grapes are considering as a full of useful and essential chemicals, however it's seed and skin are habitually contains the growth and survival properties of diverse types of pathogenic and non-pathogenic bacterial populations including $B . \quad$ subtilis, E. coli, Pseudomonas aeruginosa, Bacillus cereus, Staphylococcus aureus, Listeria monocytogenesetc (Jayaprakasha et al., 2003; Rhodes et al., 2006 and Fernandes et al., 2007).Though the antimicrobial activity of the grape extract against $E$. coli $\mathrm{O} 157: \mathrm{H} 7$ have been reported already (Kim et al., 2008), but several contaminating factors can spoilage the grapes during the cultivation and post-harvesting process by contacting with soil, air, water or animal wastes (Chen et al., 2004).

Inadequate sanitizing practices in the shop and retail markets are one of the leading sources of microbial contamination (Olaimat \& Holley et al., 2012) Presence of pathogenic bacteria such as Escherichia coli, Salmonella spp., and Shigella spp. has possessed a possible threat to the consumer creating foodborne illness. (Eni et al., 2010 and Aycicek et al., 2006). In addition, drugresistant organisms are increasing swiftly due to consumption of unhygienic raw fruits, triggering health-related concern and subsequently hampering the disease medication (Dutta \& Noor et al., 2013 and Noor \& Acharjee et al., 2013) However, implementing a new method would be highly preferable to check overall food quality and safety issues. The microbial challenge test is one of them and can assess microbial survival potential of certain foods through inoculating specific microbial communities under the diverse regulated environmental conditions. The main focusing point of such kind of in vitro microbial challenge test is to identify growth potential and to evaluate the highest growth rate of particular microbes. (Fatema et al., 2013). Thus, consumer safety must be considered by testing of food stability as well.

Till now several accessions have been done to evaluate the surviving capability of microorganisms associated with grape samples, though, which are still insufficient. Moreover, previous researches were mostly focused on the grape extract or grape seed extract. As peoples of our country commonly take grape as whole fruit and not take the extract as food suppliant, the quality of the whole fruit assessment is required for public health safety. Based on these discussed facts, the present study is designed (1) to isolate and identify drug-resistant microbes that associated with grape spoiling activities, (2) to unfold antimicrobia activity of the tested grape samples, and eventually (3) to investigate the survival capabilities of the grapes spoiling microflora by performing microbial challenge test (an efficient in vitro testing to check the viable count of microbes).

\section{MATERIAL AND METHODS}

\section{Study area, sampling and sample processing}

The present study was carried out with five groups of imported grape (Vitis vinifera) samples with Red Globe, Perlette grape, Calmeria grape, Princess and Summer Royal grape, inventing from the following locations Japan, Peru, New Zeland, Sparta and West Virginia, consecutively. Random samples were taken haphazardly from different supermarkets sites in Dhaka, Bangladesh, within a period from November 2019 to December 2019 maintaining usual protocol (APHA, 1998). For the isolation and identification of grape spoiling microbiome and mycobiome, a standard procedure was maintained taking $10 \mathrm{~g}$ of grape sample mixed with $90 \mathrm{ml}$ peptone water, the $\mathrm{pH}$ was adjusted $7.2 \pm 0.2$ and diluted up to $10^{-5}$ fold.

\section{Isolation and enumeration of spoiling microorganisms}

To test the presence of entire viable microorganisms, presence in grape samples, conventional spread plate technique was performed by taking $0.1 \mathrm{~mL}$ of each diluted sample spread onto Nutrient Agar (NA) and Sabouraud Dextrose Agar (SDA) plates (Cappauccine \& Sherman et al., 1996). Therefore, these plates were observed after 24 hours incubation at $37{ }^{\circ} \mathrm{C}$ and 48 hours incubation at $25{ }^{\circ} \mathrm{C}$ for total viable bacteria bacterial count and fungal count, respectively. 0.1 $\mathrm{mL}$ sample was collected from 10-3 and 10-5 diluted samples and extent onto MacConkey agar for the enumeration coliforms (E. coli and Klebsiella spp.) and
MFC media for fecal coliforms, respectively. Later, the agar plates were incubated for 24 hours at $37^{\circ} \mathrm{C}$ but for the faecal coliforms, the approximate temperature was $44.5{ }^{\circ} \mathrm{C}$ with carried out the random period e.g. 24 hours. To characterized the $E$. coli strains, green metallic sheen colony were observed on Eosin methylene blue (EMB) agar medium. For isolation of Staphylococcus spp and Pseudomonas spp. Mannitol Salt Agar (MSA) and Pseudomonas agar were used respectively, and $0.1 \mathrm{~mL}$ of diluted sample was spread onto these agar plates and incubated for 24 hours at $37^{\circ} \mathrm{C}$. Also, $0.1 \mathrm{ml}$ of suspension was extent onto the Listeria identification media and plates for enumeration of Listeria spp. and incubated for 24 hours at $37{ }^{\circ} \mathrm{C}$. Listeria spp. identification was listing ou by observing blue-green colonies on Listeria identification agar media. However, all those bacterial isolates were biochemically tested for further confirmation (Table 2) (Fatema et al., 2013).

\section{Enrichment of bacterial strains for enumeration}

Enrichment culture is important for viable but non-culture able (VBNC) bacterial cells or stressed cells to increase their number in detectable level for proper enumeration. (Rahman \& Noor et al., 2012 and Fatema et al., 2013). For this reason, in the present experiment to enrich Salmonella, Shigella and Vibrio spp., $1 \mathrm{~mL}$ of each broth sample was added into $9 \mathrm{~mL}$ of Alkaline Peptone Water (APW) and Selenite Cystine Broth and incubated for 6 hours at $37{ }^{\circ} \mathrm{C}$. After incubation, to isolate Vibrio, Salmonella, Shigella spp., two common isolating agar plates such as Thiosulphate Citrate Bile Salt Sucrose (TCBS) agar media and Salmonella Shigella (SS) agar media for those bacterial species were used respectively. After that, both plates were kept into the incubator at $37{ }^{\circ} \mathrm{C}$ for 48 hours to get the detectable colonies. Eventually, all the finding isolates were observed biochemically by maintaining standard procedure (APHA, 1998 and Fatema et al., 2013).

\section{Antibacterial susceptibility test}

All the bacterial isolates were spread on Muller-Hinton agar media to test the susceptibility against 15 commonly antibacterial drugs (including first, second and third-generation drugs) by using disc diffusion method (Difco, Detroit, MI) and following the typical protocol (Fatema et al., 2013). Antibiotic discs contained ampicillin (10 $\mu \mathrm{g})$, trimethoprim/sulfamethoxazole $(25 \mu \mathrm{g})$, tetracycline $(30 \mu \mathrm{g})$, ceftriaxone $(30 \mu \mathrm{g})$, imipenem $(10 \mu \mathrm{g})$, chloramphenicol $(30$ $\mu \mathrm{g})$, azithromycin $(15 \mu \mathrm{g})$, novobiocin $(30 \mu \mathrm{g})$, vancomycin $(30 \mu \mathrm{g})$, penicillin $\mathrm{G}$ $(10 \mu \mathrm{g})$, ciprofloxacin $(5 \mu \mathrm{g})$, neomycin $(30 \mu \mathrm{g})$, levofloxacin $(5 \mu \mathrm{g})$, kanamycin $(30 \mu \mathrm{g})$ and cefiximycin $(5 \mu \mathrm{g})$.

\section{Determination of antibacterial activity of grape samples}

The Agar Well Diffusion Method is a proven scientific method to test the antibacterial activity of grape sample which was previously used by (Hussain $e$ al., 2010 and Fatema $e t$ al., 2013). All the tested organisms (Bacillus spp., Pseudomonas spp., Vibrio spp., Listeria spp., Salmonella spp., Kle bsiella spp., E. coli and Staphylococcus aureus) were put into the normal saline to make a suspension comprising of $10^{6}$ cells $/ \mathrm{mL}$ (compared with McFarland standard) after that the lawns were set on Muller- Hinton agar (MHA) plates separately. After drying, sterile cork borers were used to form $8 \mathrm{~mm}$ wells. A volume of $100 \mu \mathrm{L}$ of each sample blend (with a concentration of $11 \mu \mathrm{g} / \mu \mathrm{L}$ ) was transferred into separate wells, dried and subsequently incubated at $37^{\circ} \mathrm{C}$ for 12 18 hours. Normal saline and Gentamycin $(10 \mu \mathrm{g})$ were used as a positive and negative control, respectively. The occurrence of a clear zone around the sample solution (if any) denoted the existence of antibacterial activity (Adib et al., 2008 and Fatema et al., 2013).

\section{Microbial challenge test}

\section{Samples processing}

The surface of the one chosen grape samples (Summer Royal) were washed for five times by $90 \%$ ethanol to free from the microbial association. Afterwards, 10 gm samples were mixed with $90 \mathrm{~mL}$ buffered peptone water (BPW), and then from the resultant suspensions $10 \mathrm{~mL}$ each sample aliquot with buffered peptone water, eventually centrifuged at $5000 \mathrm{rpm}$ for 5 minutes for three times, using with $90 \%$ alcohol centrifuged for two times and finally centrifuged was performed for $70 \%$ alcohol (Fatema et al., 2013). The resultant pellets after centrifugation steps were collected and suspended with $9 \mathrm{~mL}$ BPW. From the suspended solution $100 \mu \mathrm{L}$ of each sample was poured on to the nutrient agar media to test the remaining growth for getting contamination-free microbial growth. The culture plates were kept in the normal refrigerator at $-4{ }^{\circ} \mathrm{C}$ until further use (Fatema et al., 2013).

\section{Microbial inoculation and growth count}

One loop full pure culture of each sample (Bacillus spp., Pseudomonas spp., Vibrio spp., Listeria spp., Salmonella spp., Kle 
bsiella spp., E. coli and Staphylococcus aureus) were poured into $9 \mathrm{~mL}$ sterile normal saline containing test tubes (Cappuccino \& Sherman et al., 1996) After 6-hours of incubation at $37^{\circ} \mathrm{C}$ (Fatema et al., 2013), the cell density was moved to around $105 \mathrm{cfu} / \mathrm{g}$ (compared with McFarland Standard OD 0.5) for each test suspension. Microbial challenge test was performed for every bacterial isolate found in grape samples. $10 \mathrm{~mL}$ of suspension from each grapes sample were inoculated with $100 \mu \mathrm{L}$ of the bacterial suspension made the initial load of $\sim 105$ cfu/gm, and the mixture was incubated at $37{ }^{\circ} \mathrm{C}$ for 15 days. No inoculation was done for control samples Finally to examine the growth pattern of the isolates, the prepared suspensions were diluted up to $10^{-6}$ folds and spread onto Luria Bertani (LB) agar media, which then observed after every 24-hour interval according to standard spread plate technique (Cappuccino \& Sherman $e t$ al., 1996 and Fatema et al., 2013).

\section{Assessment of reduction in bacterial load}

For the finding of the probable growth rate of artificially inoculated bacterial species in the samples considered, the log reduction and percent reduction were analyzed using the following formulas (AFSSA, 2008 and Fatema et al., 2013) $\log 10$ reduction $=\log 10($ initial load $)-\log 10($ final load $) \%$ Reduction $=$ $\{[\log 10$ (initial load) $-\log 10$ (final $\operatorname{load}) / \log 10$ (initial load) $\} \times 100$. The standard initial load at 0 hour of inoculation is generally considered $10^{5} \mathrm{cfu} / \mathrm{g}$, though in the present study the maximal load after 24-48 hours was also taken into account instead of the initial load stated above. Deducing the final load from the maximum growth point would conclude the accurate decay pattern of microorganisms (Fatema et al., 2013).

\section{Statistical analysis}

All the experimentations were performed individually 3 times. Every values were analysed statistically to determine the p-value done by $t$ test (Shahriar $e t$ al., 2019).

\section{RESULTS}

\section{Microbial prevalence in the tested grape samples}

The present experiment is to demonstrate consistent results since a vast amount of microorganisms including bacteria and fungi have been isolated from the tested grape samples (Table 1). Pseudomonas spp. was found to be the predominant bacterial growth on each tested samples. Staphylococcus spp. was prevalent on four samples except for the Perlette grape. Escherichia coli growth was found to be variable showing the presence on both parts of Perlette grape, on skin part of Princess grape. However, fecal coliform, Klebsiella, Shigella, Salmonella and Vibrio spp. were absent on any of the samples. Surprisingly, in the skin area of the tested samples, the number of microbial growth was higher compare to flesh portions. (Table 1).

\section{Drug resistance pattern of the bacterial isolates}

Study of antibiogram revealed that few species show sensitivity towards imipenem $(10 \mu \mathrm{g})$, cefiximycin $(5 \mu \mathrm{g})$, and kanamycin $(30 \mu \mathrm{g})$ (Figure 2). Staphylococcus species were found to be resistant against all the antibiotics except sulphamethoxazole-trimethoprim $(25 \mu \mathrm{g})$ (Figure 2). A similar scenario was found in the case of Pseudomonas with the exception of sensitivity to imipenem $(10 \mu \mathrm{g})$ and ceftriaxone $(30 \mu \mathrm{g})$ (Figure 2). All most every isolate was shown a multi-drug resistance pattern (Figure 2).

\section{Antibacterial activity of grape samples}

Our experiment did not reveal any bactericidal activity of any of the grape sample tested. However, the organic solvent extracts of grape juice show this antibacterial action, where we used only the crud fraction of the grape samples.

\section{In vitro challenge test to observe bacterial survival capability}

After 48 hours incubation of Summer Royal Grape samples with each of the 6 tested bacteria, an initial escalation pattern of microbial growth was observed by a diminishing trend (Figure 3). As the initial inoculum was introduced unnaturally within a usual microbial load $10^{5}$ cells/gm), the maximal microbial growth points were calculated after 15 days later compare with final microbial load In Summer Royal Grape samples (Figure 3, A-F), the growth of Pseudomonas spp., were reduced more than $2 \log$ whereas the reduction score for E. coli, Salmonella spp., Bacillus spp., and Klebsiella spp., were nearly $2 \log$. Even for the least isolate (Staphylococcus spp.), the reduction score was observed approximately 1-log (Figure 3).

\section{Assessment of reduction in bacterial load}

Interestingly, the reduction score for Staphylococcus spp. were estimated more than 3-log in the Summer Royal Grape samples (Figure 4). Constant percentage of reduction trend was observed for Staphylococcus spp. which was higher in the Summer Royal Grape samples (Figure 4). In Summer Royal Grape samples, the growth of Salmonella spp., Klebsiella spp., and E coli, were reduced more than 2log whereas, Bacillus spp., and Pseudomonas spp., were reduced above 1-log (Figure 4). From Figure 4, a slight change in bioburden was observed, especially in terms of Salmonella spp., and $E$. coli. The minor reduction was also determined $\quad$ for Staphylococcus spp., Bacillus spp., Klebsiella spp., $\quad$ and Pseudomonas spp., nevertheless, the reductions were very insignificant and hence the overall findings are evidently suggestive of grape to be supportive for microbial growth.

Table 1 Bacterial and fungal growth on grape samples

\begin{tabular}{lcccccc}
\hline Sample & Part & $\begin{array}{c}\text { TVC } \\
\text { (cfu/g) }\end{array}$ & $\begin{array}{c}\text { Fungi } \\
(\mathbf{c f u} / \mathbf{g})\end{array}$ & $\begin{array}{c}\text { E. coli } \\
(\mathbf{c f u} / \mathbf{g})\end{array}$ & $\begin{array}{c}\text { Staphylococcus } \\
\text { (cfu/g) }\end{array}$ & $\begin{array}{c}\text { Pseudomonas } \\
\text { (cfu/g) }\end{array}$ \\
\hline \multirow{2}{*}{ Red Globe (n=5) } & Skin & $7.6 \times 10^{6}$ & $5.0 \times 10^{4}$ & 0 & $2.7 \times 10^{4}$ & $3.2 \times 10^{2}$ \\
& Flesh & $1.2 \times 10^{5}$ & $8.0 \times 10^{3}$ & 0 & $3.0 \times 10^{3}$ & $1.0 \times 10^{2}$ \\
Perlette (n=5) & Skin & $2.0 \times 10^{6}$ & $1.0 \times 10^{4}$ & $8.2 \times 10^{3}$ & 0 & $2.6 \times 10^{2}$ \\
& Flesh & $1.8 \times 10^{4}$ & $7.0 \times 10^{2}$ & $3.0 \times 10^{2}$ & 0 & $4.9 \times 10^{5}$ \\
Calmeria (n=5) & Skin & $5.1 \times 10^{5}$ & $2.6 \times 10^{5}$ & 0 & $7.1 \times 10^{4}$ & $3.2 \times 10^{2}$ \\
& Flesh & $4.8 \times 10^{4}$ & $2.4 \times 10^{4}$ & 0 & $1.0 \times 10^{2}$ & $4.8 \times 10^{2}$ \\
Princess (n=5) & Skin & $8.1 \times 10^{7}$ & $1.7 \times 10^{5}$ & $9.0 \times 10^{2}$ & $4.2 \times 10^{3}$ & $1.1 \times 10^{2}$ \\
& Flesh & $8.8 \times 10^{5}$ & $1.8 \times 10^{4}$ & 0 & $3.6 \times 10^{4}$ & $1.5 \times 10^{1}$ \\
Summer Royal (n=5) & Skin & $8.1 \times 10^{5}$ & $1.6 \times 10^{5}$ & 0 & $5.1 \times 10^{6}$ & $3.28 \times 10^{4}$ \\
& Flesh & $4.4 \times 10^{4}$ & $1.0 \times 10^{4}$ & 0 & $1.5 \times 10^{2}$ & $4.3 \times 10^{2}$ \\
\hline
\end{tabular}

** After incubation no growth of fecal coliform, Salmonella, Shigella, Klebsiella and Vibrio spp. was monitored. All the isolates on selective medium were subject to several biochemical tests for further identification. Results are demonstrated in Table 2. 
Table 2 Biochemical test results of the isolated bacterial species

\begin{tabular}{|c|c|c|c|c|c|c|c|c|c|c|c|}
\hline \multirow[b]{2}{*}{ Sample } & \multicolumn{3}{|c|}{ Triple Sugar Iron Agar } & \multirow[b]{2}{*}{ MR } & \multirow[b]{2}{*}{$\mathbf{V P}$} & \multirow[b]{2}{*}{$\frac{0}{\frac{0}{g}}$} & \multirow[b]{2}{*}{ 荀 } & \multirow[b]{2}{*}{ 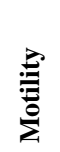 } & \multirow{2}{*}{ 总 } & \multirow[b]{2}{*}{ 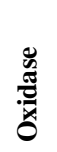 } & \multirow{2}{*}{$\begin{array}{l}\text { Suspected } \\
\text { organism }\end{array}$} \\
\hline & Slant & Butt & Gas & & & & & & & & \\
\hline \multirow{2}{*}{ Red Globe } & A & A & - & - & - & + & - & - & + & - & Staphylococcus spp. \\
\hline & A & A & - & - & - & + & - & + & - & + & Pseudomonas spp. \\
\hline \multirow{2}{*}{ Perlette } & A & A & + & + & - & + & - & + & + & - & Escherichia coli \\
\hline & A & $\mathrm{K}$ & - & - & - & + & + & + & - & + & Pseudomonas spp. \\
\hline \multirow{2}{*}{ Calmeria } & A & $\mathrm{K}$ & - & - & - & + & - & - & + & - & Staphylococcus spp. \\
\hline & A & $\mathrm{K}$ & - & - & - & - & - & + & - & - & Pseudomonas spp. \\
\hline \multirow{3}{*}{ Princess } & A & A & + & + & - & + & - & + & - & - & Escherichia coli \\
\hline & A & A & - & - & - & - & - & - & + & - & Staphylococcus spp. \\
\hline & A & A & - & - & - & + & + & + & - & + & Pseudomonas spp. \\
\hline \multirow{2}{*}{ Summer Royal } & A & K & - & - & - & + & - & - & + & - & Staphylococcus spp. \\
\hline & A & $\mathrm{K}$ & - & - & - & - & - & + & - & - & Pseudomonas spp. \\
\hline
\end{tabular}
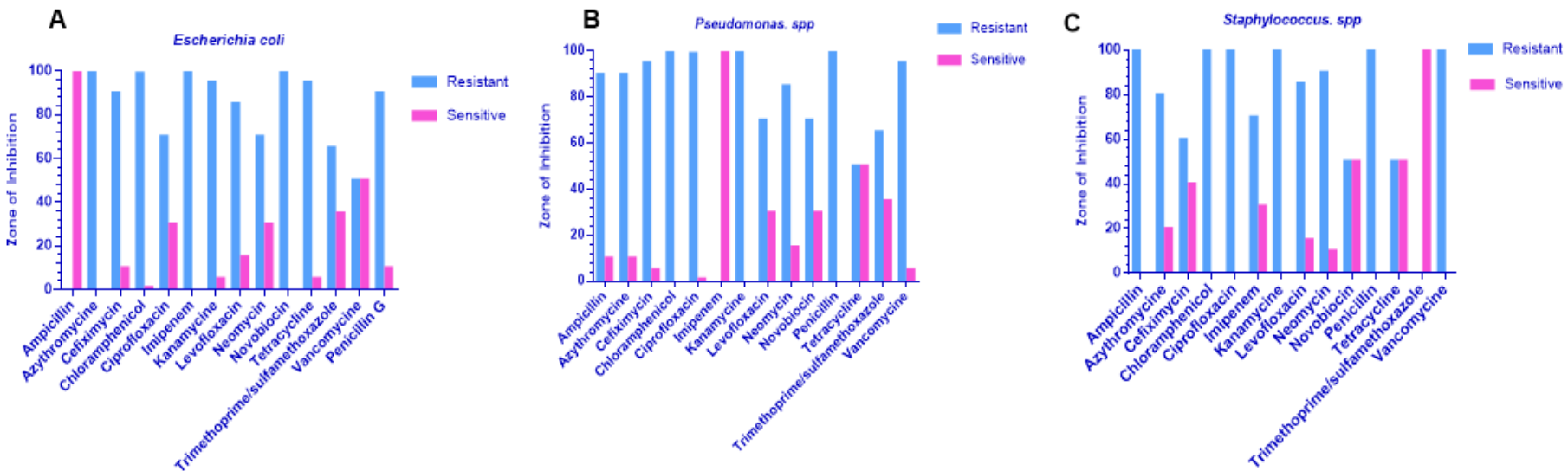

Figure 2 Resistant and susceptible pattern of (A) E.coli, (B) Pseudomonas spp., (C) Staphylococcus spp. against different types of antibiotics. All experiments were carried out three times with $95 \%$ accuracy and presented data ware statistically analyzed by showing the standard errors consider as $5 \%$.
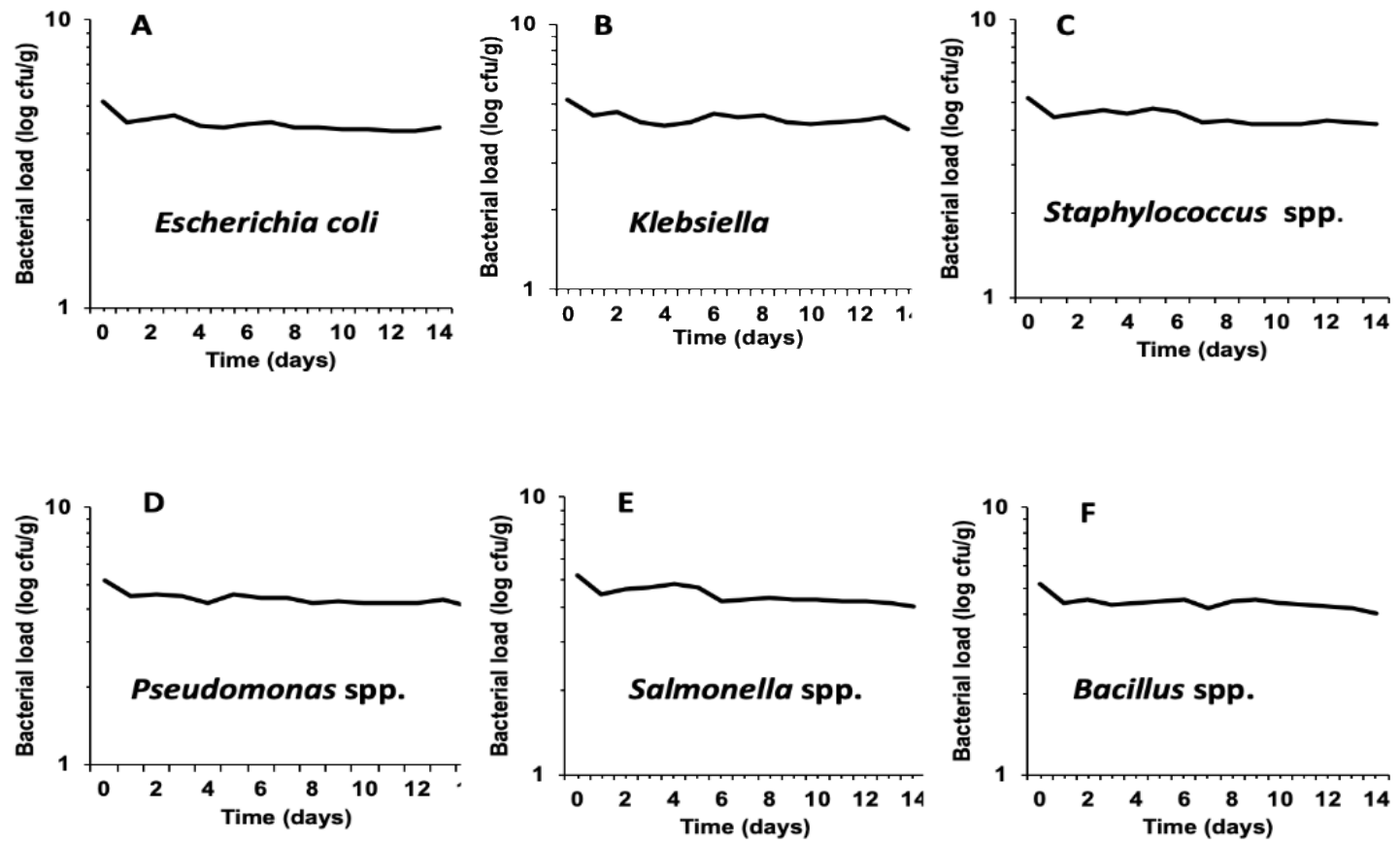

Figure 3 Bacterial Survival of in Summer Royal Grape sample (A - F). The turbidity of bacterial culture (A: Escherichia coli, B: Klebsiella spp., C: Staphylococcus spp., D: Psuedomonas spp., E: Salmonella spp., F: Bacillus spp.) were adjusted with the standard solution of McFarland (OD 6000.5$)$ and then inoculate into the processed grape samples. enumeration of bacterial growth was determined by the colony forming units of per gram of samples (cfu/g) on LB platesat every 24 hours interval up to 15 days. 
A

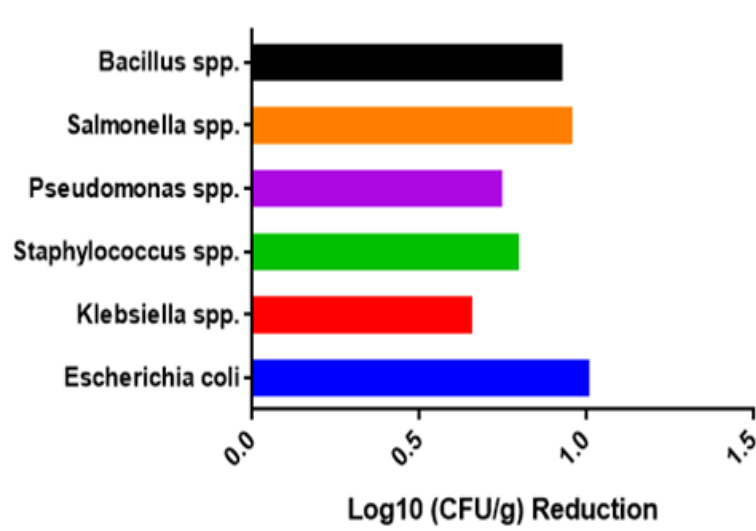

B

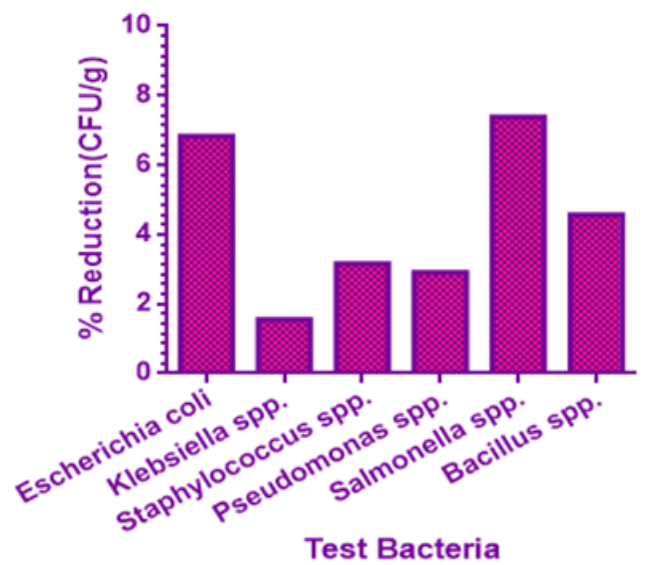

Figure 4 Growth decay and survival capacity of the test isolate in Summer Royal Grape. Reduction in bacterial growth (CFU/gm) in Summer Royal Grape samples. A. Log10 reduction, B. \%reduction.

\section{DISCUSSION}

The outbreak of deadly diseases due to health unconsciousness, unhealthy, unhygienic sanitization, water and environment pollution, incompatible medication, and microbial contamination of food is common (Rahman \& Noor et al., 2012). This situation became more annihilating by the proliferation of drug resistance phenomenon of the contaminating bacterial population ( $\operatorname{Raz} e t$ al., 2005; Chowdhury et al., 2012; Dutta et al., 2013 and Fatema et al., 2013). As evident from the earlier examinations, most of the intestinal difficulties and diseases are significantly caused by contaminated food and water, apparently suggestive of harbouring possible microbial pathogens (Rahman \& Noor et al., 2012; Chowdhury et al., 2012; Dutta et al., 2013 and Fatema et al., 2013). The current study is to demonstrate consistency results since a vast amount of microorganisms including bacteria and fungi were isolated from the tested grape samples. Interestingly, in the skin area of the tested samples, the number of microbial growth was extremely momentous compare to flesh portions. (Table 1). Improper handling of the fruits and poor hygienic conditions subsequently entry of the pathogenic microbes could be the possible cause of contamination. Besides, inappropriate antibiotic treatment during the processing steps of fruits and also in the time of ingestion contamination might happen. During processing by washing with contaminated water by the fruit seller, it might also spread microbial contamination before consumption. The extensive increasing of this harmful difficulty can occur due to the drug resistance nature of contaminating bacteria (Dutta et al., 2013 and Fatema et al., 2013). Demonstration of multidrug resistant bacteria from grapes sample is the public health concern. In general, the increasing rate of antibiotic-resistant bacteria is alarming in the developing countries due to the misuse and overuse of antibiotics and Selfprescription (Dutta et al., 2013 and Fatema et al., 2013). The findings from the present study will be suggestive to hinder the spread of antibiotic resistance genes in the environment and could help to solve medication complicacy of foodborne diseases. However, all the bacterial isolates found in grape samples were highly resistant to commonly available antibiotics (Figure 2).

Presence of anti-bacterial traits in the Summer Royal Grape samples is the significant finding of the recent experiment. Although some of the samples from this experiment was exhibited such trait against E.coli, Staphylococcus and Pseudomonas; yet this results indicated that the importance of maintaining hygienic during handling and after harvesting of the grape samples moreover, throughout the distribution to consumers. The products should be ensured with no microbial contamination with natural medicinal properties. Different studies recommended using microorganismkilling agent to preserve food items. This technique could be a potential substitution of chemical drugs and could save us from the possible side effects of synthetic medicines, besides it may increase the longevity of the food and subsequently consumer safety (Fatema et al., 2013).

Evaluation of the growth pattern and survival potential of the isolated microorganisms from grape samples was the final phase of the present study for spoilage extent as already delineated. The in vitro microbiological challenge test was employed for the first time in Bangladesh to perform grape research. To date, the knowledge on the survival capacity of grape spoiling bacteria is insufficient. Even so, the knowledge of microbial quality assurance is helpful to optimize the grape storage and distribution to the consumers; hence it will contribute to increase the knowledge of food safety, maintain the hygiene and quality assurance. Microbial challenge tests are usually performed on pharmaceutical products as well as food industry (Adib et $a l ., 2008$ and Fatema $e t$ al., 2013). However, application of such sort of in vitro test will add a new dimension in the branch of fruit microbiology to minimize the risk food intoxication (Hussain et al., 2010 and Fatema et al., 2013). In consequence, based on the hypothesis microbiological quality of grape was examined and checked antimicrobial activity in the course of time. we estimated the longevity of the culturable microorganisms in the grape samples. The shelf-life of grapes associated culturable microorganisms were determined by the present study.

The results of the present research demonstrated 1-log microbial reduction an average in all Summer Royal Grape samples, except for the Pseudomonas spp. which showed relatively higher reduction frequency The reduction pattern of all other bacteria was also taken into the consideration and prepared an overall data set, which sufficiently met the objective of the present study. Reducing contamination of the Staphylococcus spp. could be the indicator of nutrient limiting condition for the particular microorganisms to survive in the grape samples. Rest of the contaminants like pathogenic bacterial species were reduced with an average range of 2-log which depicts the quality of the product after a certain time of storage condition. From this present research, it is clear that the grape has an excellent capability to influence the microbial growth \& development and subsequently getting sustainable food quality and better shelf life. In general, the present research explored microbial communities in the imported grape samples. Knowledge from this study could help to improve public health sectors by developing medication against foodborne illness. Although the initial research on grapes has demonstrated the potency of microbial quality, for the advanced strategies of fruits quality and maintaining proper hygiene could be possible by applying extensive molecular studies on virulence gene, metabolites, toxins and growth-promoting factor. Eventually, microbial stimulation in the present research under controlled condition could be an interest to maintain shelf life and product quality of fruits with consumer safety. In near future, the similar studies on different types of fruits would be the further microbial growth surveillance following the product quality which will increase the ability of repress the contamination of grapes as well as others eatable fruits with microbial proliferation.

\section{CONCLUSIONS}

Overall, the current experiment attempted to reduce the implication of foodborne illnesses of the consumers. Results from the present study distinctly contribute a complete bacteriological profile of imported grape samples, which has public health importance. Such an approach can be simulated by using resource-poor settings lacking extensive molecular biological studies on microbial virulence genes, microbial toxins or metabolites, and eventually the growth-promoting factors. Further analysis with the advanced experiment in different fruit items with the antibacterial trait of the alcoholic extract of grape juice would reveal the growth and social relationship of microbial communities compare to fruit types, which may avail to intuition the product shelf-life and the consumer safety.

Author contributions: This work was carried out in collaboration between all authors. All the authors have accepted responsibility for the entire content of this submitted manuscript and approved the submission. Authors TA, AS, MA, and TR performed experiments. TA, AS, MA, TR, and TBE conceived the study and designed the experimental procedures. TA, AS, MRM and TBE designed and planned the studies, supervised the experiments. TBE also acted for all correspondences. TA, AS, MRM and TBE participated in the manuscript draft and has thoroughly checked and revised the manuscript for necessary changes in 
format, grammar and English standard. All authors read and approved the final version of the manuscript. All authors read and approved the manuscript.

Acknowledgments:We thank Stamford University Bangladesh for providing us the facilities to carry out the experiments. However, the authors received no specific funding for this work.

Competing interest: The authors declare that they have no competing interest.

\section{REFERENCES}

Adib, AM., Ahmad, F., Idris, MS. (2008). Synthesis and antimicrobial activity of 4',5,7-trihydroxy-3'-prenylflavanone. Journal of Chemical Sciences, 120 (5), 469-473. https://doi.org/10.1007/s12039-008-0073-5

AFSSA (Agence Franc,aise de Se'curite' Sanitaire des Aliments), (2008) Technical guidance document on shelf-life studies for Listeria monocytogenes in ready-to-eat foods.

APHA (American Public Health Association) (1998). Standard methods for the examination of water and wastewater. American Public Health Association, Washington, D.C

Aycicek, H., Oguz, U. and Karci, K. (2006). Determination of total aerobic and indicator bacteria on some raw eaten vegetables from whole sellers in Ankara. Turkey. International Journal of Hygiene and Environmental Health, 209, 197 201. https://doi.org/10.1016/j.ijheh.2005.07.006

Bertelli, AAA., Das, DK. (2009). Grapes, Wines, Resveratrol, and Heart Health. Journal of Cardiovascular Pharmacology, 54, 468-476. https://doi.org/10.1097/FJC.0b013e3181bfaff3

Cappuccino, JG., Sherman, N. (1996). Microbiology - A Laboratory Manual. The Benjamin/Cummings Publishing Co., Inc., Menlo Park, California.

Chen, L., Ingham, BH., Ingham, SC. (2004). Survival of Penicillium expansum and Patulinproduction on stored apple after wash treatments. Journal of Food Science, 69, 669-675. https://doi.org/10.1111/j.1750-3841.2004.tb18016.x

Chowdhury, MAKA. (2012). Evolving antibiotic resistance: A great threat to medical practice. Bangladesh Journal of Medical Science, 11(1), 1-3. https://doi.org/10.3329/bjms.v11i1.9814

Demir, BS., Serindag, O. (2006). Determination of boron in grape (Vitis vinifera) by azomethine $\mathrm{H}$ spectrophotometric method. Eurasian Journal of Analytical Chemistry, 1, 11-18. https://doi.org/10.12973/ejac/77002

Dutta, S., Hassan, MR., Rahman, F., Jilani, MSA., Noor, R. (2013). Study of antimicrobial susceptibility of clinically significant microorganisms isolated from selected areas of Dhaka, Bangladesh. Bangladesh Journal of Medical Science, 12(1), 34-42. https://doi.org/10.3329/bjms.v12i1.13351

Eni, AO., Oluwawemitan, IA., Oranusi, US. (2010). Microbial quality of fruits and vegetables sold in Sango Ota, Nigeria. African Journal of Food Science, 4(5), 291-296.

Fatema, N., Acharjee, M., Noor, R. (2013). Microbiological profiling of imported apples and demonstration of bacterial survival capacity through in vitro challenge test. American Journal of Microbiological Research, 1(4), 98-104. https://doi.org/10.12691/ajmr-1-4-6

Fernandes, J., Comes, F., Couto, J. A. and Hogg, T. (2007). The antimicrobial effect of wine on Listeria innocua in a model stomach system. Food Control, 18, 1477-1483.https://doi.org/10.1016/j.foodcont.2006.11.003

Fuleki, T., Ricardo-Da-Silva, MJ. (2003). Effects of cultivar and processing method on the contents of catechins and procyanidins in grape juice. Journal of Agriculture and Food Chemistry, 51, 640-646. https://doi.org/10.1021/jf020689m García-Alonso, M., de Pascual-Teresa, S., Santos-Buelga, C., Rivas-Gonzalo, JC. (2004). Evaluation of the antioxidant properties of fruits. Food Chemistry, 84, 13-18. https://doi.org/10.1016/S0308-8146(03)00160-2

Gonzalez-Paramas, S., Rivas-Gonzalo, JC. (2004). Flavanol content and antioxidant activity in winery byproducts. Journal of Agricultural and Food Chemistry, 52, 234-238. https://doi.org/10.1021/jf0348727

Hussain, A., Wahab, S., Zarin, I., Hussain, MDS. (2010). Antibacterial activity of the leaves of Coccinia indica (W and A) of India. Advances in Biological Research, 4(5), 241-248.

Jayaprakasha, GK., Selvi, T., Sakariah, KK. (2003). Antibacterial and antioxidant activities of grape (Vitis vinifera) seed extracts. Food Research International, 36, 117-122. https://doi.org/10.1016/S0963-9969(02)00116-3

Kim, TJ., Weng, WL., Stojanovic, J., Lu, Y., Jung, YS., Silva, JL. (2008) Antimicrobial effect of water-soluble muscadine seed extracts on E. coli O157:H7. Journal of Food Protection, 71, 1465-1468. https://doi.org/10.4315/0362-028X-71.7.1465

Lopez-Velez, M., Martínez-Martínez, F., Del Valle-Ribes, C. (2003). The study of phenolic compounds as natural antioxidants in wine. Food Science and Nutrition, 43, 233-244. https://doi.org/10.1080/10408690390826509

Marambaud, P., Zhao, HT., Davies, P. (2005). Resveratrol promotes clearance of Alzheimer's disease amyloid-beta peptides. Journal of Biological Chemistry, 280 (45), 37377-37382. https://doi.org/10.1074/jbc.M508246200

Yadav, M., Jain, S.,Bhardwaj, A., Nagpal, R., Puniya, M., Tomar, R., Singh, V., Parkash, O., Prasad, GBKS., Marotta, F., Yadav, H. Biological and medicinal properties of Grapes and their bioactive constituents: An update. Journal of Medicinal Food, 06/2009.https://doi.org/10.1089/jmf.2008.0096

Noor, R., Acharjee, M., Ahmed, T., Das, KK., Paul, L., Munshi, SK., Urmi, NJ. Rahman, F., Alam, Z. (2013). Microbiological study of major sea fish available in local markets of Dhaka city, Bangladesh.Journal of Microbiology, Biotechnology and Food Sciences, 2 (4), 24202430.https://doaj.org/article/7fde4260556148608f1c50d33e2f15f2

O’Byrne, DJ., Devaraj, S., Grundy, SM., Jialal, I. (2002). Comparison of the antioxidant effects of Concord grape juice flavonoids alpha-tocopherol on markers of oxidative stress in healthy adults. The American Journal of Clinical Nutrition, 76, 1367-1374. https://doi.org/10.1093/ajcn/76.6.1367

Olaimat, AN., Holley, RA. (2012). Factors influencing the microbial safety of fresh produce: A review. Food Microbiology, 32, $1-19$ https://doi.org/10.1016/j.fm.2012.04.016

Park, YK., Park, E., Kim, JS., Kang, MH. (2003). Daily grape juice consumption reduces oxidative DNA damage and plasma free radical levels in healthy Koreans. Mutation Research, 529 (1-2), 77-86. https://doi.org/10.1016/S00275107(03)00109-X

Rahman, F., Noor, R. (2012). Prevalence of pathogenic bacteria in common salad vegetables of Dhaka metropolis. Bangladesh Journal of Botany, 41(2), 150-162. https://doi.org/10.3329/bjb.v41i2.13442

Raz, R., Edelstein, H., Grigoryan, L., Haaijer-Ruskamp, FM. (2005). Selfmedication with antibiotics by a population in Northern Israel. The Israel Medical Association Journal,7(11), 722-725

Rhodes, PL., Mitchell, JW., Wilson, MW., Melton, LD. (2006). Antilisterial activity of grape juice and grape extracts derived from Vitis vinifera variety Ribier. International Journal of Food Microbiology, 107, 281-286. https://doi.org/10.1016/j.ijfoodmicro.2005.10.022

Samad, MA., Adam, NA., Hadi, SMA., Omar, NH., Zain, ZM. (2012). Antimicrobial properties of white Malaga grape grown in Malaysia. International Journal of Undergraduates Studies, 1(1), 44-47.

Selga, A., Sort, X., Bobet, R. and Torres, JL. (2004). Efficient one pot extraction and depolymerization of grape (Vitis vinifera) pomace procyanidins for the preparation of antioxidant thio-conjugates. Journal of Agricultural and Food Chemistry, 52, 467-473. https://doi.org/10.1021/jf0350481

Shahriar, A., Akter, T., Kobra, AT., Emran, TB., Mallick, J., Dutta, M. (2019). Isolation of pathogenic and non-pathogenic microbial stains from different types of sea fish samples and their quality assessment with antibiogram properties. Journal of Advanced Microbiology, 19(1), 10https://doi.org/10.9734/jamb/2019/v19i130185

Viljanen, K., Sundberg, S., Ohshima, T., Heinonen, M. (2002). Carotenoids as antioxidants to prevent photooxidation. European Journal of Lipid Science and Technology, 104, 353-359. https://doi.org/10.1002/1438-9312

Walzem, RL. (2008). Wine and health: state of proofs and research needs Inflammopharmacology, 16, 265-271. https://doi.org/10.1007/s10787-008-8027$\underline{6}$

Waterhouse, AL. (2002). Wine phenolics. Annals of The New York Academy of Sciences, 957, 21-36. https://doi.org/10.1111/j.1749-6632.2002.tb02903.x

Yilmaz, Y., Toledo, RT. (2004). Major flavonoids in grape seeds and skins: antioxidant capacity of catechin, epicatechin and gallic acid. Journal of Agricultural and Food Chemistry, 52, 255-260. https://doi.org/10.1021/jf030117h 